\title{
ESTIMATING THE UNCERTAINTY OF POLICY EFFECTS IN NONLINEAR MODELS ${ }^{1}$
}

\author{
By RAY C. FAIR
}

\begin{abstract}
A method is described in this paper for estimating, by means of stochastic simulation, the asymptotic variances of multipliers for nonlinear models. It is used to estimate the uncertainty of the results of eight policy experiments for a particular model.
\end{abstract}

\section{INTRODUCTION}

ALTHOUGH MACROECONOMETRIC MODELS are widely used to analyze the effects of alternative government actions on the economy, estimates of the uncertainty of these effects are rarely, if ever, presented. This is, of course, not surprising, since most macroeconometric models are nonlinear. Unlike for linear models, formulas for the asymptotic variances of impact and dynamic multipliers are not known for nonlinear models. ${ }^{2}$ It is possible, however, to estimate these variances for nonlinear models by stochastic simulation, and the purpose of this paper is to discuss the method by which this can be done. The method is discussed in Section 2 , and results of applying the method to eight policy experiments for the model in Fair $[7,10]$ are presented in Section $3 .{ }^{3}$ Given the obvious importance of knowing how much confidence to place on the results of any particular policy experiment in a model, it is hoped that this study will stimulate others to obtain uncertainty estimates for their models similar to those presented in Section 3.

\section{THE METHOD}

The method can be applied to a model that is nonlinear in both variables and coefficients. Let $G$ denote the total number of equations in the model, $M$ the number of stochastic equations, and $N$ the total number of predetermined (both exogenous and lagged endogenous) variables. Assume (for expositional convenience only) that the model is quarterly, and let the $i$ th equation of the model for quarter $t$ be written:

$$
\phi_{i}\left(y_{i t}, \ldots, y_{G t}, z_{i t}, \ldots, z_{N t}, \beta_{i}\right)=\varepsilon_{i t}
$$

$$
(i=l, \ldots, G),
$$

where the $y_{i t}$ are the endogenous variables, the $z_{i t}$ are the predetermined variables, $\beta_{i}$ is the vector of unknown coefficients in equation $i$, and $\varepsilon_{i t}$ is the error term corresponding to equation $i$. For identities, $\varepsilon_{i t}$ is zero for all $t$. Also, let $\beta$ denote the vector of all the unknown coefficients in the model, and let $\varepsilon_{z}$ denote

\footnotetext{
${ }^{1}$ The research described in this paper was financed by grant $\$ 0 C 77-03274$ from the National Science Foundation.

${ }^{2}$ For the formulas for linear models, see Dhrymes [6], Schmidt [15], and Brissimis and Gill [3].

${ }^{3}$ Estimates similar to those in Section 3 do not appear to have been obtained before for nonlinear models. The closest study in this respect is probably that of Haitovsky and Wallace [12], where estimates of the total forecasting uncertainty for the FRB-MIT and Michigan models are obtained for different policy rules.
} 
the $M$-component vector of the error terms of the stochastic equations for quarter $t$. For simplicity it will be assumed that $\varepsilon_{t} \sim N(0, \Omega)$ for all $t$, although the following discussion can be modified to incorporate different assumptions about the distribution of $\varepsilon_{t}$.

Before discussing the method, it should be noted that although the method relies heavily on the use of stochastic simulation, it can be explained without going into the details of the simulation procedures. Because of this and because these details are in part model specific, no mention of particular simulation procedures is made in this section. The exact procedures that were followed for the application of the method to the model in [7] are explained in the next section.

Let $x_{1}$ denote a particular vector of exogenous variable values over the period of interest, and let $y_{i t k}^{e}\left(\Omega, \beta, x_{1}\right)$ denote the $k$-quarter-ahead expected value of variable $i$ for quarter $t$ conditional on $\Omega, \beta$, and $x_{1} \cdot{ }^{4}$ Although it is generally not possible for a nonlinear model to derive an analytic expression for $y_{i t k}^{e}\left(\Omega, \beta, x_{1}\right)$, it can be estimated by stochastic simulation. If $\Omega$ and $\beta$ were known, one would merely draw for each trial a set of error terms from the $N(0, \Omega)$ distribution and solve the model for this set using $\beta$ and $x_{1}$. In this case the stochastic simulation estimate of the expected value would differ from the true expected value only because of a finite number of draws. In practice, of course, $\Omega$ and $\beta$ are not known, and so one must use estimates of these for the stochastic simulation. Let $\hat{\Omega}$ and $\hat{\beta}$ denote these estimates, and let $\tilde{y}_{i t k}^{e}\left(\hat{\Omega}, \hat{\beta}, x_{1}\right)$ denote the stochastic simulation estimate of $y_{i t k}^{e}\left(\Omega, \beta, x_{1}\right)$ based on these estimates. $\tilde{y}_{i t k}^{e}\left(\hat{\Omega}, \hat{\beta}, x_{1}\right)$ will, of course, differ from $y_{i t k}^{e}\left(\Omega, \beta, x_{1}\right)$ not only because of a finite number of draws but also because of the use of $\hat{\Omega}$ and $\hat{\beta}$ instead of $\Omega$ and $\beta .^{5}$

As will be seen, the method requires that $y_{i t k}^{e}\left(\Omega, \beta, x_{1}\right)$ be estimated a number of times. One possibility is to estimate this each time by stochastic simulation, as just discussed. This is, however, fairly expensive, and it fortunately appears to be the case for many econometric models that good approximations to the stochastic simulation estimates are the values obtained from setting the error terms to zero (i.e., to their expected values) and solving the model once. ${ }^{6}$ In other words, for many models $\hat{y}_{i t k}^{e}\left(\hat{\beta}, x_{1}\right)$ is quite close to $\tilde{y}_{i t k}^{e}\left(\hat{\Omega}, \hat{\beta}, x_{1}\right)$, where $\hat{y}_{i t k}^{e}\left(\hat{\beta}, x_{1}\right)$ denotes the $k$-quarter-ahead solution value of variable $i$ for quarter $t$ obtained from setting the error terms to zero. In the following discussion both of these options for estimating the expected values are considered, although it is likely in most applications that the cheaper option will be used.

Assume now that one is interested in examining the effects on the expected values of the endogenous variables of changing the exogenous variable values

\footnotetext{
${ }^{4}$ All expected values in this paper are also conditional on the values of the endogenous and exogenous variables up to the beginning of the simulation period. For a $k$-quarter-ahead forecast for quarter $t$, the beginning quarter is $t-k+1$.

${ }^{5}$ It should also be noted that although $\hat{\beta}$ is used for this stochastic simulation, the uncertainty from the coefficient estimates is not taken into account. The uncertainty of $\hat{\beta}$ is taken into account later in the method.

${ }^{6}$ This result has been obtained by Nagar [13], Sowey [16], Cooper [5], Bianchi, Calzolani, and Corsi [2], Calzolani and Corsi [4], and Fair [9]. The result in [9] is for the model considered in Section 3 of this paper.
} 
from $x_{1}$ to $x_{2}$. Let

$$
\delta_{i t k}^{e}=y_{i t k}^{e}\left(\Omega, \beta, x_{2}\right)-y_{i t k}^{e}\left(\Omega, \beta, x_{1}\right),
$$

which is the change in the $k$-quarter-ahead expected value of variable $i$ for quarter $t$ as a result of the change in the exogenous variable values. For $\beta$ known, the difference in the expected values in (2) is not a random variable. The uncertainty of policy effects comes from the fact that only an estimate of $\beta$ is available. This uncertainty can be estimated by stochastic simulation as follows.

Consider first the (unrealistic) case in which the distribution of $\hat{\beta}$ is known. In particular, assume that $\hat{\beta} \sim N\left(\beta^{0}, V\right)$, where $\beta^{0}$ and $V$ are known. (Again, this normality assumption can be modified.) Let $\beta^{*}$ be a particular draw from this distribution. Given $\beta^{*}$, the expected values of the endogenous variables can be estimated using first $x_{1}$ and then $x_{2}$. These expected values can be estimated either by stochastic simulation or by setting the error terms to zero. If the former is done, define $\delta_{i t k}$ to be:

$$
\delta_{i t k}=\tilde{y}_{i t k}^{e}\left(\hat{\Omega}, \beta^{*}, x_{2}\right)-\tilde{y}_{i t k}^{e}\left(\hat{\Omega}, \beta^{*}, x_{1}\right),
$$

and if the latter is done, define $\delta_{i t k}$ to be:

$$
\delta_{i t k}=\hat{y}_{i t k}^{e}\left(\beta^{*}, x_{2}\right)-\hat{y}_{i t k}^{e}\left(\beta^{*}, x_{1}\right) .
$$

For each draw of $\beta^{*}$, a value of $\delta_{\text {itk }}$ can be computed, and so by taking a number of draws it is possible to estimate the mean and variance of $\delta_{i t k}$, providing the moments exist. ${ }^{7}$ The estimate of the variance of $\delta_{i z k}$ is then an estimate of the uncertainty of the effect on the $k$-quarter-ahead expected value of variable $i$ for quarter $t$ from changing $x_{1}$ to $x_{2}$.

If the distribution of $\hat{\beta}$ is not known, which is almost always the case in practice, then some estimate of it must be used. In most cases the asympotic distribution of $\hat{\beta}$ is known to be normal and one has an estimate of the asymptotic covariance matrix of $\hat{\beta}$. Consequently, one can draw values of $\beta^{*}$ from the $N(\hat{\beta}, \hat{V})$ distribution, where $\hat{V}$ is the estimate of the asymptotic covariance matrix of $\hat{\beta}$.

This completes the description of the method. Assuming that stochastic simulation is not used to estimate the expected values of the endogenous variables, a summary of the steps involved for the method is as follows: (i) Choose a simulation period, $x_{1}$, and $x_{2}$. (ii) Choose a distribution of $\beta^{*}$, say $N(\hat{\beta}, \hat{V})$. (iii) For each draw of $\beta^{*}$, run two dynamic simulations of the model over the simulation period, one using $x_{1}$ and one using $x_{2}$, where for both simulations the error terms are set equal to zero. From these results, calculate $\delta_{\text {itk }}$ in (4) for each variable and quarter. (iv) Repeat step (iii), say, $J$ times. Let $\delta_{i k t}^{(i)}$ denote the value of $\delta_{i t k}$ computed on the

\footnotetext{
${ }^{7}$ It is, of course, not obvious that these moments exist. Sargan [14], for example, has shown in the linear case for the 2SLS and 3SLS estimators that no moments exist for the derived reduced form coefficient estimates. If in a given application the mean and variance of $\delta_{i t k}$ do not exist, then one should estimate other summary measures of the distribution, such as the median, interquartile range, mean absolute deviation, etc. For purposes of the present discussion it will be assumed that the moments exist.
} 
$j$ th trial. Then the estimated mean $\left(\bar{\delta}_{i t k}\right)$ and variance $\left(s_{i t k}^{2}\right)$ of $\delta_{i t k}$ are:

$$
\begin{aligned}
& \bar{\delta}_{i t k}=\frac{1}{J} \sum_{j=1}^{J} \delta_{i r k}^{(i)}, \\
& s_{i t k}^{2}=\frac{1}{J} \sum_{i=1}^{J}\left(\delta_{i t k}^{(j)}-\bar{\delta}_{i t k}\right)^{2} .
\end{aligned}
$$

It is important to note that in practice $\bar{\delta}_{i t k}$ in (5) will not in general be equal to $\delta_{i t k}^{e}$ in (2), the true expected value. This is true even if stochastic simulation is used to estimate the expected values of the endogenous variables, i.e., even if (3) is used to compute $\delta_{i t k}$. There are three reasons for this aside from sampling error due to a finite number of draws. First, $\hat{\Omega}$ must be used in place of $\Omega$. Second, the true distribution of $\hat{\beta}$ is not known and so must be estimated. Third, even if the true distribution of $\hat{\beta}$ were known, $\hat{\beta}$ would have to be an unbiased estimate of $\beta$. In other words, $\beta^{0}$ above would have to be equal to $\beta{ }^{8}$ In practice, then, the best that one can hope for is that $\bar{\delta}_{i t k}$ is close to $\delta_{i t k}^{e}$ and that $s_{i t k}^{2}$ is a good approximation to the true variance of the distribution of $\delta_{i t k}$.

It should finally be noted that the method is general enough to handle any combination of changes in the exogenous variables. The change from $x_{1}$ to $x_{2}$ is not, for example, restricted to a change in only one exogenous variable.

\section{AN APPLICATION}

The method was used to estimate the uncertainty of eight policy actions for the model in Fair $[7,10]$. This model consists of 97 equations, 29 of which are stochastic, and has 181 unknown coefficients to estimate (including 12 serial correlation coefficients). The model is nonlinear in variables and coefficients, the latter because of the serial correlation coefficients, which are treated for present purposes as structural coefficients. The model was estimated for the 1954I-1978II period ( 98 observations) by two-stage least squares (2SLS).

The period considered for the policy actions was 1978IV-1982IV (17 quarters). An actual ex ante forecast was first made for this period, using guessed values of the exogenous variables, and then this forecast was used as a basis for the policy experiments. ${ }^{9}$ Each experiment corresponded to changing the values of one fiscal policy variable from the values used for the base forecast. The eight fiscal policy variables are: $d_{1}$-profit tax rate; $d_{3 t}$-personal income tax rate; $d_{4 t}-$ indirect business tax rate; $d_{5 t}$-employer social security tax rate; $d_{6 r}-$ employee social security tax rate; JOBGC $C_{t}$-number of government civilian jobs in thousands; $X G_{r}$-government expenditures on goods in billions of 1972 dollars; $Y G_{t}$-transfer payments from the government to households, not counting unemployment insurance benefits, in billions of current dollars.

\footnotetext{
${ }^{8}$ If, of course, $\beta$ were known, there would be no multiplier uncertainty.

9 Although the simulation period used here is outside of the estimation period, this need not be the case. There is nothing inherent in the method that precludes within-sample experiments.
} 
For the $X G$ experiment, $X G$ was changed each quarter (from the value used for the base forecast) by 10.0 billion dollars at an annual rate. The changes in the policy variables for the other experiments were made to be roughly comparable to the $X G$ change. With respect to monetary policy, an equation explaining the behavior of the Federal Reserve is included in this model, and so monetary policy is endogenous. This equation, which is explained in Fair [8], is an equation in which the Fed "leans against the wind." As the economy expands or as inflation increases, the Fed is estimated to cause the bill rate to rise.

The exact procedure that was followed for the stochastic simulations is as follows. First, for each of the 29 stochastic equations, 2SLS coefficient estimates are available. These estimates are discussed in Fair and Parke [11]. They are based on a different set of first stage regressors for each equation. Let $\hat{\beta}$ denote the 181-component vector of the 2SLS estimates, and let $\hat{V}$ denote the estimate of the $181 \times 181$ asymptotic covariance matrix of $\hat{\beta}^{10}$ Also, let $\beta^{*}$ denote the vector of coefficient values used for a given trial.

For each trial $\beta^{*}$ was drawn from the $N(\hat{\beta}, \hat{V})$ distribution, ${ }^{11}$ and nine dynamic simulations (of 17 quarters) were run, each based on setting the error terms to zero. The first simulation was for the basic set of exogenous variable values, and each of the others was for the set after the particular policy change. The number of trials was $250 .{ }^{12}$ For each of the eight experiments, 250 values of $\delta_{i t k}$ in (4) were computed for each endogenous variable and quarter. These values were used to compute $\bar{\delta}_{i t k}$ in (5) and $s_{i t k}^{2}$ in (6). ${ }^{13}$ Note that doing eight experiments at a time saves a considerable amount of computer time: the base simulation need only be done once per trial for all eight experiments.

Results for six selected endogenous variables are presented in Table I. Results for all eight experiments are presented for real GNP and the GNP deflator, and results for the $X G$ experiment only are presented for the unemployment rate, the bill rate, the money supply, and the wage rate. The $a$ rows contain the estimated means $\left(\bar{\delta}_{i t k}\right)$, and the $b$ rows contain the estimated standard deviations $\left(s_{i t k}\right)^{14}$

${ }^{10}$ The formula for the diagonal blocks of $\hat{V}$ is presented in Amemiya [1]. The formula for the off-diagonal blocks is a generalization of that given in Theil $[17, \mathrm{pp} .499-500]$ for the linear case to take account of nonlinearity and different sets of first stage regressors. For further details see [11].

${ }^{11}$ The draws for $\beta^{*}$ were performed as follows. First, a matrix $P$ was computed such that $P P^{\prime}=\hat{V}$. This was done using the LUDECP subroutine in the IMSL library. Then 181 values of a standard normal random variable with mean 0 and variance 1 were drawn. This was done using the function RNOR, which is part of the SUPER DUPER random number generator package at Yale. Let $u$ denote the $181 \times 1$ vector of these draws. Then $\beta^{*}$ was computed as $\hat{\beta}+P u$. Since $E u u^{\prime}=I$, then $E\left(\beta^{*}-\hat{\beta}\right)\left(\beta^{*}-\hat{\beta}\right)^{\prime}=E P_{u u^{\prime}} P^{\prime}=\hat{V}$, which is as desired for the distribution of $\beta^{*}$.

${ }^{12}$ Each 17 -quarter simulation takes about 1.8 seconds of computer time on the IBM $370-158$ at Yale, and so the total time for the $250 \times 9$ simulations was about 68 minutes.

${ }^{13}$ Because of the possibility that the variances do not exist, mean absolute deviations were also computed. If the variances do not exist, one might expect the estimated variances to be more erratic than the estimated mean absolute deviations. In the present case, however, there was no evidence that this was true, and so only the results for the estimated variances are reported here.

${ }^{14}$ For the GNP deflator and the wage rate, the $a$ and $b$ row values in Table $I$ are expressed as a percentage of the level of the variable. To be more precise, let $\bar{y}_{i t k}$ denote the mean (over the 250 trials) of the $k$-quarter-ahead forecast of variable $i$ for quarter $t$ from the base simulation. Then the numbers in the $a$ rows are $100\left(\bar{\delta}_{i k k} / \bar{y}_{i n k}\right)$ and the numbers in the $b$ rows are $100\left(s_{i l k} / \bar{y}_{i t k}\right)$. 
TABLE 1

The Restuls of the STOCHAstic Simulations $a=\bar{\delta}_{i s k}$ values (estimated means).

$b=s_{i t k}$ values (estimated standard deviations).

\begin{tabular}{|c|c|c|c|c|c|c|c|c|c|c|c|c|c|c|c|c|c|c|}
\hline \multicolumn{19}{|c|}{ Quarter } \\
\hline \multirow{3}{*}{$\begin{array}{l}\text { Policy } \\
\text { Variable } \\
\text { Changed }\end{array}$} & \multirow{2}{*}{\multicolumn{2}{|c|}{$\begin{array}{l}1978 \\
\text { IV }\end{array}$}} & \multicolumn{3}{|c|}{1979} & \multirow{3}{*}{ IV } & \multicolumn{4}{|c|}{1980} & \multicolumn{4}{|c|}{1981} & \multicolumn{4}{|c|}{1982} \\
\hline & & & I & II & III & & I & II & III & IV & I & II & IIII & IV & I & II & III & IV \\
\hline & $\ddot{k}:$ & 1 & 2 & 3 & 4 & & 6 & 7 & 8 & 9 & 10 & 11 & 12 & 13 & 14 & 15 & 16 & 17 \\
\hline \multicolumn{19}{|c|}{ Real GNP (billions of 1972 dollars at an annual rate) } \\
\hline \multirow[t]{2}{*}{$X G$} & $a$ & 9.4 & 12.1 & 12.9 & 13.0 & 12.4 & 11.5 & 10.4 & 9.4 & 8.4 & 7.5 & 6.8 & 6.2 & 5.6 & 5.2 & 4.8 & 4.5 & 4.2 \\
\hline & $b$ & 1.0 & 0.7 & 0.9 & 1.1 & 1.3 & 1.4 & 1.5 & 1.6 & 1.7 & 1.7 & 1.7 & 1.8 & 1.8 & 1.8 & 1.9 & 1.9 & 2.0 \\
\hline \multirow[t]{2}{*}{$\triangle O B G C$} & $a$ & 11.5 & 10.9 & 9.8 & 8.5 & 6.9 & 5.4 & 4.0 & 2.7 & 1.5 & 0.6 & -0.2 & -0.8 & -1.4 & -1.8 & -2.1 & -2.3 & -2.5 \\
\hline & $b$ & 0.3 & 0.8 & 1.2 & 1.5 & 1.8 & 2.1 & 2.3 & 2.4 & 2.5 & 2.6 & 2.7 & 2.8 & 2.8 & 2.9 & 3.0 & 3.1 & 3.1 \\
\hline \multirow[t]{2}{*}{$d_{3}$} & $a$ & 0.0 & 2.6 & 4.0 & 4.9 & 5.5 & 5.8 & 5.9 & 6.0 & 5.9 & 5.8 & 5.7 & 5.6 & 5.6 & 5.5 & 5.4 & 5.3 & 5.3 \\
\hline & $b$ & 0.0 & 1.5 & 2.1 & 2.3 & 2.5 & 2.5 & 2.5 & 2.4 & 2.4 & 2.3 & 2.3 & 2.2 & 2.2 & 2.2 & 2.2 & 2.2 & 2.2 \\
\hline \multirow[t]{2}{*}{$d_{6}$} & $a$ & 0.0 & 3.4 & 5.2 & 6.3 & 6.9 & 7.3 & 7.3 & 7.3 & 7.2 & 7.0 & 6.8 & 6.7 & 6.5 & 6.4 & 6.3 & 6.2 & 6.1 \\
\hline & $b$ & 0.0 & 2.1 & 2.9 & 3.2 & 3.4 & 3.5 & 3.4 & 3.3 & 3.2 & 3.1 & 3.0 & 2.9 & 2.9 & 2.9 & 2.9 & 2.9 & 2.9 \\
\hline \multirow[t]{2}{*}{$Y G$} & $a$ & 0.3 & 1.2 & 2.0 & 2.8 & 3.4 & 3.8 & 4.2 & 4.5 & 4.7 & 4.8 & 4.9 & 4.9 & 4.9 & 4.9 & 4.9 & 4.9 & 4.9 \\
\hline & $b$ & 0.3 & 0.5 & 0.8 & 1.1 & 1.4 & 1.6 & 1.7 & 1.9 & 2.0 & 2.1 & 2.1 & 2.2 & 2.2 & 2.2 & 2.2 & 2.2 & 2.2 \\
\hline \multirow[t]{2}{*}{$d_{1}$} & $a$ & 0.0 & 0.2 & 0.6 & 1.1 & 1.8 & 2.7 & 3.8 & 4.9 & 6.0 & 7,0 & 7.7 & 8.3 & 8.7 & 9.0 & 9.1 & 9.2 & 9.2 \\
\hline & $b$ & 0.0 & 0.1 & 0.3 & 0.6 & 0.9 & 1.3 & 2.0 & 2.7 & 3.4 & 4.0 & 4.5 & 4.9 & 5.2 & 5.3 & 5.5 & 5.5 & 5.5 \\
\hline \multirow[t]{2}{*}{$d_{5}$} & $a$ & 0.0 & 0.1 & 0.4 & 0.8 & 1.3 & 2.0 & 2.9 & 3.8 & 4.7 & 5.4 & 6.0 & 6.5 & 6.8 & 7.0 & 7.0 & 7.0 & 7.0 \\
\hline & $b$ & 0.0 & 0.1 & 0.2 & 0.4 & 0.6 & 1.0 & 1.6 & 2.1 & 2.7 & 3.2 & 3.6 & 3.9 & 4.1 & 4.2 & 4.3 & 4.3 & 4.3 \\
\hline \multirow{2}{*}{$d_{4}$} & $a$ & 1.4 & 2.5 & 3.2 & 3.6 & 3.9 & 4.1 & 4.2 & 4.2 & 4.2 & 4.2 & 4.2 & 4.1 & 4.1 & 4.1 & 4.0 & 4.0 & 4.0 \\
\hline & $b$ & 0.5 & 0.6 & 0.7 & 0.7 & 0.8 & 0.8 & 0.9 & 0.9 & 1.0 & 1.0 & 1.1 & 1.1 & 1.1 & 1.2 & 1.2 & 1.2 & 1.3 \\
\hline
\end{tabular}


TABLE I (continued)

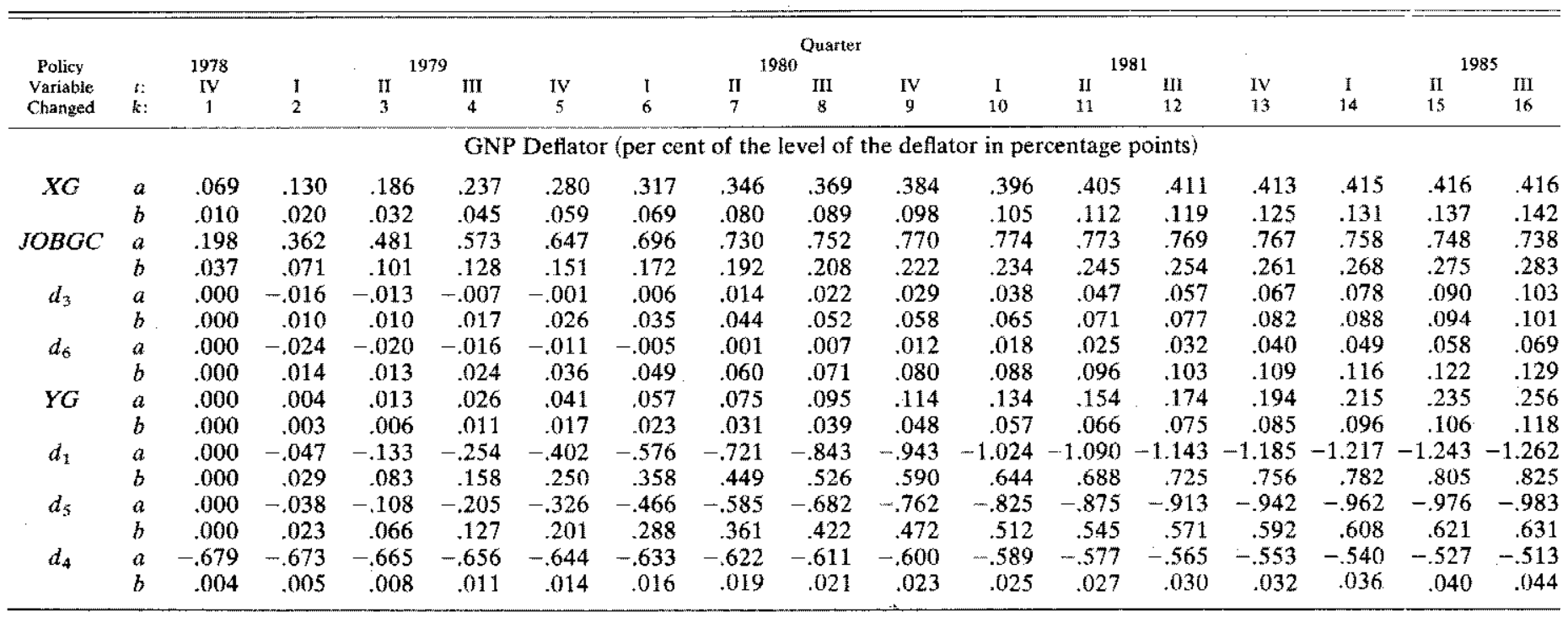


TABLE I (continued)

\begin{tabular}{|c|c|c|c|c|c|c|c|c|c|c|c|c|c|c|c|c|c|c|}
\hline \multirow{3}{*}{$\begin{array}{l}\text { Policy } \\
\text { Variable } \\
\text { Changed }\end{array}$} & \multicolumn{3}{|c|}{1978} & \multicolumn{2}{|c|}{1979} & \multirow[b]{2}{*}{ IV } & \multicolumn{4}{|c|}{1980} & \multicolumn{4}{|c|}{1981} & \multicolumn{4}{|c|}{1982} \\
\hline & $t:$ & IV & I & II & III & & I & II & III & IV & I & II & III & IV & 1 & II & III & IV \\
\hline & $k:$ & 1 & 2 & 3 & 4 & 5 & 6 & 7 & 8 & 9 & 10 & 11 & 12 & 13 & 14 & 15 & 16 & 17 \\
\hline \multicolumn{19}{|c|}{ Unemployment Rate (percentage points) } \\
\hline$X G$ & $\begin{array}{l}a \\
b\end{array}$ & $\begin{array}{r}-.175 \\
.041\end{array}$ & $\begin{array}{r}-.364 \\
.056\end{array}$ & $\begin{array}{r}.454 \\
.059\end{array}$ & $\begin{array}{r}-.478 \\
.062\end{array}$ & $\begin{array}{r}-.469 \\
.064\end{array}$ & $\begin{array}{r}-.442 \\
.066\end{array}$ & $\begin{array}{r}-.405 \\
.069\end{array}$ & $\begin{array}{r}-.366 \\
.073\end{array}$ & $\begin{array}{r}-.328 \\
.077\end{array}$ & $\begin{array}{r}-.295 \\
.081\end{array}$ & $\begin{array}{r}-.266 \\
.085\end{array}$ & $\begin{array}{r}-.242 \\
.088\end{array}$ & $\begin{array}{r}-.222 \\
.092\end{array}$ & $\begin{array}{r}-.207 \\
.095\end{array}$ & $\begin{array}{r}-.195 \\
.097\end{array}$ & $\begin{array}{r}-.186 \\
.099\end{array}$ & $\begin{array}{r}-.180 \\
.101\end{array}$ \\
\hline \multicolumn{19}{|c|}{ Bill Rate (percentage points) } \\
\hline$X G$ & $\begin{array}{l}a \\
b\end{array}$ & $\begin{array}{l}.169 \\
.070\end{array}$ & $\begin{array}{l}.291 \\
.083\end{array}$ & $\begin{array}{l}.363 \\
.087\end{array}$ & $\begin{array}{l}.411 \\
.091\end{array}$ & $\begin{array}{l}.438 \\
.094\end{array}$ & $\begin{array}{l}.448 \\
.098\end{array}$ & $\begin{array}{l}.447 \\
.102\end{array}$ & $\begin{array}{l}.438 \\
.108\end{array}$ & $\begin{array}{l}.424 \\
.111\end{array}$ & $\begin{array}{l}.408 \\
.115\end{array}$ & $\begin{array}{l}.390 \\
.118\end{array}$ & $\begin{array}{l}.373 \\
.120\end{array}$ & $\begin{array}{l}.356 \\
.121\end{array}$ & $\begin{array}{l}.340 \\
.121\end{array}$ & $\begin{array}{l}.324 \\
.121\end{array}$ & $\begin{array}{l}.310 \\
.121\end{array}$ & $\begin{array}{l}.296 \\
.121\end{array}$ \\
\hline \multicolumn{19}{|c|}{ Money Supply (billions of current dollars at an annual rate) } \\
\hline$X G$ & $\begin{array}{l}a \\
b\end{array}$ & $\begin{array}{l}0.53 \\
0.39\end{array}$ & $\begin{array}{l}1.22 \\
0.95\end{array}$ & $\begin{array}{l}1.96 \\
1.57\end{array}$ & $\begin{array}{l}2.68 \\
2.18\end{array}$ & $\begin{array}{l}3.33 \\
2.76\end{array}$ & $\begin{array}{l}3.90 \\
3.30\end{array}$ & $\begin{array}{l}4.39 \\
3.78\end{array}$ & $\begin{array}{l}4.82 \\
4.22\end{array}$ & $\begin{array}{l}5.18 \\
4.62\end{array}$ & $\begin{array}{l}5.51 \\
4.99\end{array}$ & $\begin{array}{l}5.80 \\
5.34\end{array}$ & $\begin{array}{l}6.08 \\
5.67\end{array}$ & $\begin{array}{l}6.33 \\
5.98\end{array}$ & $\begin{array}{l}6.59 \\
6.29\end{array}$ & $\begin{array}{l}6.84 \\
6.60\end{array}$ & $\begin{array}{l}7.09 \\
6.90\end{array}$ & $\begin{array}{l}7.35 \\
7.20\end{array}$ \\
\hline \multicolumn{19}{|c|}{ Wage Rate (per cent of the level of the wage rate in percentage points) } \\
\hline$X G$ & $\begin{array}{l}a \\
b\end{array}$ & $\begin{array}{l}.018 \\
.010\end{array}$ & $\begin{array}{l}.058 \\
.027\end{array}$ & $\begin{array}{l}.103 \\
.045\end{array}$ & $\begin{array}{l}.145 \\
.061\end{array}$ & $\begin{array}{l}.183 \\
.076\end{array}$ & $\begin{array}{l}.214 \\
.088\end{array}$ & $\begin{array}{l}.240 \\
.098\end{array}$ & $\begin{array}{l}.259 \\
.106\end{array}$ & $\begin{array}{l}.274 \\
.112\end{array}$ & $\begin{array}{l}.284 \\
.117\end{array}$ & $\begin{array}{l}.291 \\
.121\end{array}$ & $\begin{array}{l}.296 \\
.125\end{array}$ & $\begin{array}{l}.298 \\
.128\end{array}$ & $\begin{array}{l}.299 \\
.131\end{array}$ & $\begin{array}{l}.299 \\
.134\end{array}$ & $\begin{array}{l}.299 \\
.137\end{array}$ & $\begin{array}{l}.298 \\
.140\end{array}$ \\
\hline
\end{tabular}

NOTE: $X G$ was changed each quarter fron its value for the base forecast by 10.0 billion dollars at an annual rate. The changes in the other policy yariables were made to be roughly comparable to this. 
The general properties of the model are discussed elsewhere, and so no attempt will be made here to provide a complete explanation of the $a$ row values. A few of the main differences in these values across experiments will, however, be noted. One of the important features of the model that should be kept in mind in the following discussion is its "microeconomic" basis. Included as explanatory variables in the consumption and labor supply equations, for example, are variables that one expects from microeconomic theory to affect the consumption and labor decisions of a utility maximizing household: the wage rate, the price level, interest rates, tax rates, nonlabor income, and the initial value of wealth. In particular, a higher price level has, other things being equal, a negative effect on consumption.

Some of the important differences across the $a$ row values are the following. First, the two expenditure changes ( $X G$ and $J O B G C$ ) result in much faster initial responses than do the tax changes. This is a common property of macroeconometric models. The $J O B G C$ experiment is more inflationary than is the $X G$ experiment, primarily because it led to a larger initial decrease in the unemployment rate (not shown in Table I). The higher inflation rate in the JOBGC experiment led the Fed to raise the bill rate more than it did in the $X G$ experiment (also not shown in Table I), which led to a less expansionary economy in the JOBGC experiment after the first quarter. The decreases in the profit tax rate $\left(d_{1}\right)$ and the employer social security tax rate $\left(d_{5}\right)$ led to less inflation than otherwise, and this is one of the reasons for the increase in real output in these two experiments. (As noted above, the price level has, other things being equal, a negative effect on demand in the model.) The decrease in the indirect business tax rate $\left(d_{4}\right)$ also led to a lower GNP deflator than otherwise, in this case primarily because indirect business tax rates are included in the GNP deflator.

It is interesting to note that the decreases in the personal income tax rate $\left(d_{3}\right)$ and the employee social security tax rate $\left(d_{6}\right)$ led to an initial decrease in the rate of inflation. A decrease in either of these two rates has, other things being equal, a positive effect on the labor force (one of the "microeconomic" features of the model) and thus a positive effect on the unemployment rate. An increase in the unemployment rate in turn has a negative effect on the rate of inflation. This indirect negative effect of $d_{3}$ and $d_{6}$ on the rate of inflation was large enough to lead to lower initial rates of inflation in the two experiments. This effect is exactly reversed for the increase in transfer payments $(Y G)$, which has, other things being equal, a negative effect on the labor force.

Consider now the uncertainty estimates in the $b$ rows. In particular, consider first the values for real GNP for the last quarter of the period. The least uncertain of the cases is the $d_{4}$ experiment, with an estimated standard error of 1.3 billion dollars. This is followed by the $X G$ experiment ( 2.0 billion dollars), and then by the $d_{3}$ and $Y G$ experiments ( 2.2 billion dollars each). The most uncertain are the $d_{1}$ and $d_{5}$ experiments ( 5.5 and 4.3 billion dollars, respectively). This general pattern also holds for the GNP deflator, although for this variable the standard error for the last quarter for the $X G$ experiment of .148 percentage points is slightly larger than the standard errors for the $d_{3}, d_{6}$, and $Y G$ experiments $(.108$, .136 , and .130 percentage points, respectively). 
For the most part the standard errors increase as the horizon lengthens. The primary exception to this is in the $X G$ experiment for real GNP, where the twoand three-quarter-ahead standard errors are less than the one-quarter-ahead error. The reason for this is hard to explain and not very interesting, but it is explained in the following footnote. ${ }^{15}$ The fact that the standard errors in Table I generally increase as the horizon lengthens is not inconsistent with the fact that the standard errors presented in Brissimis and Gill [3, Table I, p. 468] for Klein's Model I generally decrease as the horizon lengthens. The results in [3] are for a one-period (impulse) change in the particular policy variable, whereas the present results are for a sustained (step) change.

The standard errors for the money supply and the wage rate (presented for the $X G$ experiment only) are generally larger as a percentage of the $a$ row values than are the standard errors for the other variables. As reported elsewhere ([8] and [9]), the demand for money equations and the wage rate equation are on a number of statistical criteria some of the weakest equations of the model, and this reflects itself in the present case in fairly large $b$ row values for the money supply and the wage rate. The standard errors for the bill rate, on the other hand, which primarily reffect the statistical quality of the Fed behavioral equation, are fairly small. They are between about one-third and one-fourth of the corresponding $a$ row values.

In general, the standard errors in Table I appear fairly small, although this view obviously depends on one's initial priors. The present results are consistent with the results in [9], where estimates of the total forecasting uncertainty of the model are presented. For these estimates the contribution of the uncertainty of the coefficient estimates to the total uncertainty is in general relatively small. In conclusion, however, it should be noted that the present method does not account for the uncertainty from the possible misspecification of the model, and so estimates like those in Table I are merely lower bounds of the true uncertainty of policy effects in the model.

\section{Yale University}

Manuscript received December, $1978 ;$ revision received September, 1979.

\footnotetext{
${ }^{15}$ First, the $X G$ experiment results in a large initial change in sales of goods, something which is not true of any of the other experiments. Second, the production equation in the model is in log form and has a serially correlated error. The log of sales is one of the explanatory variables in this equation. Therefore, the change in production in the first quarter is proportional, among other things, to the change in sales in the first quarter times $e^{\hat{\rho} \hat{u}-1}$, where $\hat{\rho}$ is the estimate of the serial correlation coefficient and $\hat{u}_{-1}$ is the estimated error term from the previous quarter. The change in production in the second quarter is proportional to the change in sales in the second quarter times $e^{\hat{\rho}^{2} \hat{u}_{-t}}$. Since $\hat{\rho}$ is less than one, $\hat{u}_{1}$ contributes less to the two-quarter-ahead forecast than it does to the onequarter-ahead forecast. The uncertainty of $\hat{\rho}$ thus contributes more to the uncertainty of the one-quarter-ahead forecast than it does to the others, and this effect is large enough in the $X G$ experiment (because of the multiplicative nature of the error term and the change in sales) to lead to an overall standard error for real GNP that is larger in the first quarter than it is in the second and third quarters.
} 


\section{REFERENCES}

[1] Amemiya, TAKeshi: "The Nonlinear Two-Stage Least-Squares Estimator," Journal of Econometrics, 2 (1974), 105-110.

[2] Bianchi, C., G. CAlzolari, AND P. CoRsi: "Divergences in the Results of Stochastic and Deterministic Simulation of an Italian Non-Linear Econometric Model," in Simulation of Systems, ed. by L. Dekker. Amsterdam: North-Holland Publishing Co., 1976.

[3] BRISSIMIS, SOPHOCLES N., AND LEONARD GILL: "On the Asymptotic Distribution of Impact and Interim Multipliers," Econometrica, 46 (1978), 463-469.

[4] CAlzolari, Grorgio, AND PaOlo Corsi: "Stochastic Simulation as a Validation Tool for Econometric Models," paper presented at IIASA Seminar, Laxenburg, Vienna, September $13-15,1977$.

[5] COOPER, J. PhIl.r.rP: Development of the Monetary Sector, Prediction and Policy Analysis in the FRB-MIT-Penn Model. Lexington: D.C. Heath \& Co., 1974.

[6] Dhrymes, Phoebus J.:"Restricted and Unrestricted Reduced Forms: Asymptotic Distribution and Relative Efficiency," Econometrica, 41 (1973), 119-134.

[7] FaIr, RAY C.: A Model of Macroeconomic Activity. Volume II: The Empirical Model. Cambridge: Ballinger Publishing Co., 1976.

[8] - "The Sensitivity of Fiscal-Policy Effects to Assumptions about the Behavior of the Federal Reserve," Econometrica, 46 (1978), 1165-1179.

[9] —_: "Estimating the Expected Predictive Accuracy of Econometric Models," International Economic Review, forthcoming.

[10] - " The Fair Model as of November 1, 1978," mimeo.

[11] FAIr, RAy C., AND William R. PARKe: "Fuil Information Estimates of a Nonlinear Macroeconometric Model," Journal of Econometrics, forthcoming.

[12] HAITOVSKY, YOEL, AND NEIL WALLACE: "A Study of Discretionary and Nondiscretionary Monetary and Fiscal Policies in the Context of Stochastic Macroeconometric Models," in The Business Cycle Today, ed. by Victor Zarrowitz. New York: Columbia University Press, 1972.

[13] NAGAR, A. L.: "Stochastic Simulation of the Brookings Econometric Model," in The Brookings Model: Some Further Results, ed. by James S. Duesenberry, Gary Fromm, Lawrence R. Klein, and Edwin Kuh. Chicago: Rand McNally \& Co., 1969.

[14] SARGAN, J. D.: "The Existence of the Moments of Estimated Reduced Form Coefficients," Discussion Paper No. A6, LSE Econometrics Programme, 1976.

[15] SCHMIDT, PETER: "The Asymptotic Distribution of Dynamic Multipliers," Econometrica, 41 (1973), 161-164.

[16] SOWEY, ERIC R.: "Stochastic Simulation for Macroeconomic Models: Methodology and Interpretation," in Econometric Studies of Macro and Monetary Relations, ed. by Alan A. Powell and Ross A. Williams. Amsterdam: North-Holland Publishing Co., 1973.

[17] Theil., Henri: Principles of Econometrics, New York: John Wiley and Sons, 1971. 